\title{
Risk Factors of Pancreatitis after Percutaneous Transhepatic Biliary Stent Implantation in Patients with Distal Malignant Biliary Obstruction
}

Nan Jia

Shengjing Hospital of China Medical University

Zhihui Chang

Shengjing Hospital of China Medical University

Zhaoyu Liu ( $\square$ liuzy1226@126.com )

Shengjing Hospital of China Medical University https://orcid.org/0000-0002-5523-845X

\section{Research}

Keywords: DMBO, PTBS, Acute pancreatitis, Risk factors

Posted Date: December 16th, 2020

DOI: https://doi.org/10.21203/rs.3.rs-127787/v1

License: (c) (i) This work is licensed under a Creative Commons Attribution 4.0 International License.

Read Full License 


\section{Abstract}

Purpose Percutaneous transhepatic biliary stent implantation (PTBS) has been widely used in the treatment of malignant obstructive jaundice (MBO) 『which is an effective palliative therapy. The goal of the research was to explore the risk factors of postoperative pancreatitis in patients who had received PTBS.

Materials and Methods This study retrospectively included 248 patients with distal malignant biliary obstruction (DMBO) who received PTBS from 2014 to 2019. The risk factors of postoperative pancreatitis such as clinical characteristics, laboratory and stent variables were evaluated by logistic regression analysis.

Results Pancreatitis occurred in 51 (20\%) patients, all of whom were mild pancreatitis. Multivariate analysis showed that stent implantation across the duodenal papilla, preoperative (within 3 days) administration of proton pump inhibitors (PPIs) were independent risk factors that related to pancreatitis $(\mathrm{OR}=13.242,95 \% \mathrm{Cl}: 1.729-101.405 ; \mathrm{P}=0.013 ; \mathrm{OR}=2.113,95 \% \mathrm{Cl}: 1.024-4.36 ; \mathrm{P}=0.043$, respectively), while preoperative administration of antibiotics was a protective factor $(\mathrm{OR}=0.466,95 \% \mathrm{Cl}: 0.226-0.961$; $P=0.039)$.

Conclusion Patients with DMBO who underwent PTBS across the duodenal papilla were more likely to developing postoperative pancreatitis. Preoperative (within 3 days) administration of PPIs was also an independent risk factor for postoperative pancreatitis. Furthermore, preoperative administration of antibiotics may lower the risk of pancreatitis.

\section{Introduction}

PTBS has become a recognized palliative therapy for patients with malignant obstructive jaundice, who are not suitable for surgery [1-3]. Biliary stents can be placed percutaneously or endoscopically [4-7]. Previous studies suggested the incidence of complications after biliary stent implantation is relatively high [8]. Common complications of PTBS include biliary infection, hemobilia, acute pancreatitis, biliarycardiac reflex etc. Acute pancreatitis is a critical but rare complication, which may result in poor prognosis $[1,9,10]$.

Previous studies showed that risk factors of pancreatitis after endoscopic retrograde biliary stent implantation include previous pancreatitis, sphincter of Oddi dysfunction (SOD), difficult cannulation, precut sphincterotomy, main pancreatic duct injection and so on. However, studies on the risk factors of pancreatitis after PTBS are scarce. The pathogenesis of pancreatitis following PTBS is still unclear [11, 12]. A pathogenesis was reported by Andrea et al. [13] who revealed that compression of the pancreatic duct orifice due to medial deflection of biliary stents leads to pancreatitis. According to clinical experience, patients with DMBO is more likely to develop postoperative pancreatitis than high biliary obstruction. The risk factors of pancreatitis after PTBS have not been sufficiently reported. Therefore, the 
present study was designed to investigate risk factors of acute pancreatitis after PTBS for DMBO. We hope these findings will help with clinical treatments in future.

\section{Materials And Methods}

\section{Patient}

According to the enrollment criteria including patients who underwent PTBS successfully for distal malignant biliary stricture, 256 patients were involved in this research between January 2014 and December 2019. However, 3 of them were excluded due to preoperative pancreatitis, and 5 were excluded because of incomplete clinical data. Finally, 248 patients (137 males and 111 females; age range: 3291 years) were included. In this study, DMBO was defined as obstruction involving the common bile ducts. The diagnosis of MBO was based on clinical presentation, imaging findings, serum tumor markers and bilirubin levels. All included patients were divided into two groups according to whether developing acute pancreatitis after PTBS. Risk factors of pancreatitis after PTBS were assessed by analyzing clinical characteristics, stent parameters and laboratory variables. All collected data are summarized in Table 1. 
Table 1

Included variables and occurrence of postoperative pancreatitis

\begin{tabular}{|c|c|c|c|}
\hline Variables & $\begin{array}{l}\text { Pancreatitis }(n= \\
\text { 51) }\end{array}$ & $\begin{array}{l}\text { Without pancreatitis }(\mathrm{n}= \\
\text { 197) }\end{array}$ & $\mathbf{P}$ \\
\hline Sex (Male) & $23(45.1)$ & 114(57.9) & 0.103 \\
\hline Age, years (median) & 72 & 70 & 0.374 \\
\hline Diabetes & $15(29.4)$ & $61(31)$ & 0.831 \\
\hline Primary disease & & & 0.522 \\
\hline Originate from bile duct & $21(41.2)$ & $52(26.4)$ & \\
\hline Originate from pancreas & 17(33.3) & 114(57.9) & \\
\hline Originate from other parts of ampulla & $13(25.5)$ & $31(15.7)$ & \\
\hline Stent type & & & 0.101 \\
\hline Cook & $18(36)$ & $39(20.6)$ & \\
\hline Cordis & $5(10)$ & $13(6.9)$ & \\
\hline Bard & $13(26)$ & $82(43.4)$ & \\
\hline Antai & $14(28)$ & $55(29.1)$ & \\
\hline Stent diameter (mm) & & & 0.552 \\
\hline 8 & $4(7.8)$ & $21(10.7)$ & \\
\hline 10 & $47(92.2)$ & 176(89.3) & \\
\hline Stent length $(₫ 50 \mathrm{~mm})$ & $42(82.4)$ & $151(76.6)$ & 0.383 \\
\hline Pancreatic ducts visualization (PTC) & $7(13.7)$ & $29(14.7)$ & 0.858 \\
\hline One-stage stent implantation & $8(15.7)$ & $38(19.3)$ & 0.556 \\
\hline $\begin{array}{l}\text { Stent implantation across the duodenal } \\
\text { papilla }\end{array}$ & $49(96.1)$ & $149(75.6)$ & 0.001 \\
\hline Time of operation (Min) & 10(19.6) & $44(22.3)$ & 0.675 \\
\hline Preoperative albumin (mean $\pm \mathrm{SD}, \mathrm{g} / \mathrm{L}$ ) & $32.759 \pm 3.957$ & $33.240 \pm 3.972$ & 0.596 \\
\hline $\begin{array}{l}\text { Preoperative alkaline phosphatase } \\
\text { (median, U/L) }\end{array}$ & 264.7 & 348 & 0.01 \\
\hline $\begin{array}{l}\text { Preoperative total bilirubin (median, } \\
\mu \mathrm{mol} / \mathrm{L} \text { ) }\end{array}$ & 124.9 & 132.5 & 0.983 \\
\hline Preoperative white blood cell > $10 \times 10^{9} / \mathrm{L}$ & $1(2)$ & $31(15.7)$ & 0.009 \\
\hline Preoperative administration of PPIs & $27(52.9)$ & $67(34)$ & 0.013 \\
\hline
\end{tabular}




\begin{tabular}{|llll|}
\hline Variables & Pancreatitis $(n=$ & $\begin{array}{l}\text { Without pancreatitis }(n= \\
\text { 197 })\end{array}$ & $P$ \\
\hline Preoperative administration of antibiotics & $24(47.1)$ & $109(55.3)$ & 0.292 \\
\hline Preoperative fever $\left(\varangle 37.5^{\circ} \mathrm{C}\right)$ & $9(17.6)$ & $40(20.3)$ & 0.672 \\
\hline MPD obstruction & $31(60.8)$ & $135(68.5)$ & 0.296 \\
\hline In-stent restenosis & $1(2)$ & $16(8.1)$ & 0.121 \\
\hline
\end{tabular}

Intervention process

Local anesthesia was performed by intramuscular injection of $2 \%$ lidocaine hydrochloride. Puncture points were selected according to the location of the target bile duct. Ultrasound-guided puncture was performed to establish the biliary tract operation pathway. The site of bile duct obstruction was determined via cholangiography. After that, the appropriate stent was chosen to lie across the obstructive site. Stent should cover the stricture completely, which need to be at least $1 \mathrm{~cm}$ longer than the stricture. Types of stents included E-Luminexx Biliary Stent (Bard Peripheral Vascular Inc., Tempe, AZ, U.S.A.), Biliary Stent (Cook Ireland Ltd. Limerick, Ireland), SMART Control Nitinol Stent System (Cordis corporation, Ciudad Mexico), Shape Memory Nitinol Stent and Transport System (Beijing Antai Biomedical Materials Co. LTD, Beijing, China). And all of them are covered stents. All surgical procedures were performed in accordance with the standard guideline. Weather to implant the stent in one-stage operation is determined by the patient's general status and liver function. External biliary drainage for 3-5 days is required in patients with two-stage operation. Whether the stent is implanted across the duodenal papilla and which type stent to choose depends on the location and length of the obstruction, as well as the physician's clinical experience. The process was shown in the Fig. 1 and Fig. 2.

Acute pancreatitis

The diagnosis of acute pancreatitis was based on the Atlanta classification of acute pancreatitis. The diagnostic criteria were abdominal pain, serum amylase and/or lipase levels $\geq 3$ times the upper limit of normal value, and imaging manifestations consistent with acute pancreatitis. Patients who met two or more above criteria were diagnosed as pancreatitis. Using Common Terminology Criteria for Adverse Events (CTCAE), version 4 to assess the severity of acute pancreatitis $[14,15]$.

\section{Statistical analysis}

Mann-Whitney U-test and the Chi-square test were used to compare and analyze continuous variables and categorical variables, respectively. Statistically significant variables in univariate logistic regression analysis $(P<0.1)$ were incorporated into multivariate analysis to identify independent risk factors. Variables considered to be influential in previous studies can also be included in multivariate analysis. All statistical analysis was performed by SPSS software, version 25.0 (SPSS Inc, Chicago, IL). A P value! 0.05 was considered statistically significant. 


\section{Results}

Patient characteristics

PTBS was successfully achieved in all patients. The condition of primary disease is as follows: 73 originate from bile duct, 131 originate from pancreas and 44 originate from other parts of ampulla. Among the 248 patients, 17 patients had in-stent restenosis, 46 patients were implanted biliary stent in one-stage surgery, 198 patients underwent biliary stent implantation across the duodenal papilla (Table 1).

\section{Acute Pancreatitis After PTBS}

The diagnosis of pancreatitis was detected within 24 hours following PTBS in all cases. In all patients with pancreatitis, the increase of amylase and lipase was detected in emergency laboratory after presenting symptoms such as abdominal pain, nausea and vomiting. The Incidence of pancreatitis after PTBS is $20 \%$, which is higher than that in previous studies. The grade of pancreatitis was mild in all cases. The serum amylase and lipase levels restored to normal within 3-7 days following conservative therapy in all patients.

Risk factors analysis

On univariate analysis, stent type, stent implantation across the duodenal papilla (OR $=7.893,95 \% \mathrm{Cl}$ : 1.850-33.675; $P=0.005)$, preoperative white blood cell count $>10 \times 10^{9} / \mathrm{L}(\mathrm{OR}=0.107,95 \% \mathrm{Cl}: 0.014-$ $0.804 ; \mathrm{P}=0.03)$, preoperative alkaline phosphatase level $(\mathrm{OR}=0.998,95 \% \mathrm{Cl}: 0.997-1 ; \mathrm{P}=0.044)$ and preoperative(within 3 days) administration of proton pump inhibitors(PPIs) (OR $=2.183,95 \% \mathrm{Cl}$ : 1.1704.073; $P=0.014)$ were significant influence factors for pancreatitis $(P \otimes 0.1)$. However, other factors had no significant effect on the morbidity of postoperative pancreatitis (Table 2). 
Table 2

Univariate logistic regression analysis of risk factors for pancreatitis after PTBS

\begin{tabular}{|c|c|c|c|}
\hline \multirow[t]{2}{*}{ Variables } & \multicolumn{3}{|c|}{ Univariate analysis } \\
\hline & OR & $95 \% \mathrm{Cl}$ & $P$ \\
\hline Sex (Male) & 1.672 & $0.9-3.108$ & 0.104 \\
\hline Age & 1.011 & $0.984-1.038$ & 0.434 \\
\hline Diabetes & 0.929 & $0.474-1.822$ & 0.83 \\
\hline Primary disease & 0.896 & $0.567-1.415$ & 0.637 \\
\hline Stent type & 0.762 & $0.579-1.001$ & 0.051 \\
\hline Stent diameter & 1.184 & $0.677-2.069$ & 0.553 \\
\hline Stent length ( $₫ 50 \mathrm{~mm})$ & 1.422 & $0.644-3.139$ & 0.384 \\
\hline Pancreatic ducts visualization (PTC) & 0.922 & $0.379-2.243$ & 0.857 \\
\hline One-stage stent implantation & 0.778 & $0.338-1.792$ & 0.556 \\
\hline Stent implantation across the duodenal papilla & 7.893 & $1.850-33.675$ & 0.005 \\
\hline Time of operation & 0.848 & $0.393-1.829$ & 0.674 \\
\hline Preoperative albumin & 0.97 & $0.897-1.049$ & 0.44 \\
\hline Preoperative alkaline phosphatase & 0.998 & $0.997-1$ & 0.044 \\
\hline Preoperative total bilirubin & 1 & $0.997-1.003$ & 0.929 \\
\hline Preoperative white blood cell $>10 \times 10^{9} / \mathrm{L}$ & 0.107 & $0.014-0.804$ & 0.03 \\
\hline Preoperative administration of PPIs & 2.183 & $1.170-4.073$ & 0.014 \\
\hline Preoperative administration of antibiotics & 0.718 & $0.387-1.331$ & 0.292 \\
\hline Preoperative fever $\left(\varangle 37.5^{\circ} \mathrm{C}\right)$ & 0.841 & $0.378-1.870$ & 0.671 \\
\hline MPD obstruction & 0.712 & $0.376-1.347$ & 0.296 \\
\hline In-stent restenosis & 0.226 & $0.029-1.748$ & 0.154 \\
\hline
\end{tabular}

Stent type, stent implantation across the duodenal papilla, preoperative alkaline phosphatase level, preoperative (within 3 days) administration of PPIs and preoperative administration (within 3 days) of antibiotics were included in the multivariate analysis, which revealed that stent implantation across the duodenal papilla (OR $=13.242,95 \% \mathrm{Cl}: 1.729-101.405 ; \mathrm{P}=0.013)$, preoperative administration of PPIs (OR $=2.113,95 \% \mathrm{Cl}: 1.024-4.36 ; \mathrm{P}=0.043)$ were independent risk factors for developing acute pancreatitis, while preoperative administration of antibiotics $(\mathrm{OR}=0.466,95 \% \mathrm{Cl}: 0.226-0.961 ; \mathrm{P}=0.039)$ was a 
protective factor (Table 3). Furthermore, stent type was also an independent factor, and the incidence of pancreatitis is as follows: Cook $36 \%$, Cordis $10 \%$, Bard $26 \%$, Antai $28 \%$, respectively.

Table 3

Multivariate logistic regression analysis of risk factors for pancreatitis after PTBS

\begin{tabular}{|llll|}
\hline Variables & \multicolumn{4}{l|}{ multivariate analysis } \\
\hline Stent type & OR & $95 \% \mathrm{Cl}$ & $\mathrm{P}$ \\
\hline Stent implantation across the duodenal papilla & 13.242 & $1.729-101.405$ & 0.013 \\
\hline Preoperative alkaline phosphatase & 0.999 & $0.997-1$ & 0.088 \\
\hline Preoperative administration of PPIs & 2.113 & $1.024-4.36$ & 0.043 \\
\hline Preoperative administration of antibiotics & 0.466 & $0.226-0.961$ & 0.039 \\
\hline
\end{tabular}

\section{Discussion}

PTBS has been used in patients with malignant obstructive jaundice who are not suitable for surgery. Compared with endoscopic retrograde cholangiopancreatography (ERCP) (3\%-10\%), the morbidity of pancreatitis after PTBS is lower $(0.8 \%-5.1 \%)[1,9,16]$. In this research, the morbidity of postoperative pancreatitis was $20 \%$, which is higher than that in previous studies. That's probably because this research only selected patients with distal malignant biliary tract obstruction. Some scholars believe that postoperative pancreatitis is more likely to occur in patients with relatively low obstruction, which probably owing to a higher incidence of stimulation of the pancreas during the procedure.

To the best of our knowledge, studies on risk factors of acute pancreatitis after PTBS are scarce. In a previous meta-analysis, female gender, difficult cannulation, previous pancreatitis, previous post-ERCP pancreatitis (PEP), intraductal papillary mucinous neoplasm (IPMN), sphincter of Oddi dysfunction (SOD), endoscopic sphincterotomy (EST), precut sphincterotomy and main pancreatic duct injection are risk factors for post-ERCP pancreatitis $[17,18]$. Combined with previous reports and clinical experience, 20 variables were included in our study to analyze their influence on pancreatitis after PTBS (Table 1). In previous studies, main pancreatic duct injection was a risk factor of postoperative pancreatitis, while the morbidity of postoperative pancreatitis in patients who had atrophy of pancreas and dilation of main pancreatic duct significantly decreased [19]. In present study, main pancreatic duct injection and main pancreatic duct expansion were not significant risk factors $(P=0.857, P=0.296$, respectively).

Univariate analysis showed that stent type, stent implantation across the duodenal papilla, preoperative white blood cell count $>10 \times 10^{9} / \mathrm{L}$, preoperative alkaline phosphatase level and preoperative (within 3 days) administration of PPIs were significant influence factors for postoperative pancreatitis. Our results show that the OR of preoperative white blood cell count $>10 \times 10^{9} / \mathrm{L}$ was 0.107 , which suggested this variable has a protective effect. One explanation of this condition may be that clinicians usually treat 
patients who have leukocytosis with antibiotics. Meanwhile, some scholars believe that prophylactic use of antibiotics before surgery may reduce the risk of postoperative infection. Therefore, preoperative administration (within 3 days) of antibiotics was enrolled in the multivariate analysis instead of white blood cell count. Multivariate analysis showed that stent type, stent implantation across the duodenal papilla, preoperative administration of PPIs and preoperative administration of antibiotics have statistically significant difference, stent implantation across the duodenal papilla and preoperative administration of PPIs were risk factors for developing pancreatitis, while preoperative administration of antibiotics was a protective factor. The OR of alkaline phosphatase is close to 1 , which reveals that it has little influence on the occurrence of pancreatitis. In this study, the postoperative pancreatitis rate with different stent was statistically significant. However, bias such as the capacity for medical payment by patients in the choice of stents should not be ignored. Thus, our study could not properly assess whether pancreatitis rate is significantly related to stent types, and a large sample multicenter trial is necessary.

If biliary tumors involve the lower part of the common bile duct or the ampulla, it is inevitable that the stent will cross the duodenal papilla. However, stents placed across the duodenal papilla can block the discharge of pancreatic fluid, leading to acute pancreatitis [20]. Generally speaking, the length of the stent to enter the intestinal tract should be controlled within $1 \mathrm{~cm}$ to avoid the stimulation and injury of the distal end of the stent to the contralateral duodenal wall of the ampulla. If biliary tumors are located in the middle part or above of the common bile duct, the stent should not cross the duodenal papilla as far as possible, so as to retain the important function of the duodenal papilla. At this time, the lower edge of the bracket should not be too close to the duodenal papilla. If the distance between them is $<2 \mathrm{~cm}$, there may be a possibility of papilla spasm. Shunsuke Sugawara et al. [19] found that biliary stent implantation across the papilla for MBO would increase the morbidity of pancreatitis, which was consistent with the present study. Some scholars also believe that no matter whether the tumor involves the lower segment of the common bile duct and the ampulla, the stent should be placed across the duodenal papilla in order to facilitate drainage and reduce the incidence of cholangitis after stent implantation, which is still controversial and needs more clinical evidence to support [21]. When it comes to the fact that the disease indicates the need to stent across the papilla, clinicians can take preventive measures preoperatively in order to reduce the risk of pancreatitis.

PPIs combined with somatostatin are commonly used in the treatment of acute pancreatitis [22-24]. However, the prophylactic effect of using PPIs alone on the risk of acute pancreatitis is controversial since some studies suggest that its efficacy is limited to patients at high risk of postoperative pancreatitis. PPIs work on gastric wall cells and block acid production by inhibiting $\mathrm{H}^{+}-\mathrm{K}^{+}$-ATPase. However, a previous study revealed that PPIs therapy did not show benefit on alleviating systemic inflammatory response and clinical scores in severe pancreatitis patients [25]. In addition, gastric acid is an important barrier for the body to prevent abnormal colonization of bacteria in the upper digestive tract. Theoretically, inhibition of gastric acid secretion by PPIs may lead to abnormal composition and higher temporal instability of their intestinal microbiota, which may be an initiating factor for associated infections of pancreas. 
The effect of PPIs consumption on the risk of pancreatitis after PTBS has not been investigated. According to a previous study reported by Carmelo Scarpignato et al. [26], PPIs did not affect the clinical course of acute pancreatitis, so they are not recommended routinely in this clinical setting $[27,28]$. In the present study, multivariate analysis showed an increased risk of postoperative pancreatitis was associated with preoperative administration of PPIs, and the difference was statistically significant. As a consequence, the management of PPIs abuse before surgery should be emphasized.

Several studies have shown that strategies such as the administration of periprocedural antibiotic could decrease the incidence of postoperative complications. Rty S et al. [29] found that antibiotic prophylaxis effectively decreases the risk of pancreatitis. Multivariate analysis in the present study revealed that preoperative administration of antibiotics has been linked to lower incidence and severity of postoperative pancreatitis, which is an independent protective factor.

There are several limitations in our study. First, this was a single-center retrospective study, in all patients with pancreatitis, the increase of amylase and lipase was detected in emergency laboratory only after presenting symptoms such as abdominal pain, nausea and vomiting. It cannot be excluded that some patients without clinical symptoms also have the increase of amylase and lipase. Thus, the authenticity of the assessed data was relatively low to some extent. Second, clinical treatment strategies, such as stent implantation position and the selection of stent, were decided by the physician. As a result, selection bias may have inflated the results. Additionally, the uneven surgical ability of different surgeons may also cause different prognosis.

In conclusion, biliary stent implantation across the duodenal papilla may significantly increase the risk of postoperative pancreatitis. Preoperative (within 3 days) administration of PPIs was another independent risk factor. Consequently, PPIs should be used with great caution before operation. Moreover, prophylactic administration of antibiotics before PTBS may reduce the risk of pancreatitis.

\section{Abbreviations}




\begin{tabular}{|ll|}
\hline Percutaneous transhepatic biliary stent implantation & PTBS \\
\hline malignant obstructive jaundice & MBO \\
\hline distal malignant biliary obstruction & DMBO \\
\hline proton pump inhibitors & PPIs \\
\hline sphincter of Oddi dysfunction & SOD \\
\hline Common Terminology Criteria for Adverse Events & CTCAE \\
\hline endoscopic retrograde cholangiopancreatography & ERCP \\
\hline post-ERCP pancreatitis & PEP \\
\hline intraductal papillary mucinous neoplasm & IPMN \\
\hline sphincter of Oddi dysfunction & SOD \\
\hline endoscopic sphincterotomy & EST \\
\hline
\end{tabular}

\section{Declarations}

Ethics approval and consent to participate:

Not applicable

Consent for publication:

Not applicable

\section{Availability of data and materials:}

The datasets used and/or analysed during the current study are available from the corresponding author on reasonable request.

\section{Competing interests:}

The authors declare that they have no competing interests.

\section{Funding:}

The author(s) received no financial support for the research, authorship, and/or publication of this article.

\section{Authors' contributions:}

$\mathrm{NJ}$ collected and analyzed the patient data, and interpreted the results, and she was a major contributor in writing the manuscript. ZC analyzed the data and assisted in the revision of the manuscript. ZL 
developed the project and helped to edit the manuscript. All authors read and approved the final manuscript.

\section{Acknowledgments:}

We would like to thank all of our colleagues and authors who cooperated with us by preparing the full text of the papers.

\section{Ethical approval:}

For this type of study formal consent is not required.

\section{References}

1. B YYA BRBL. B YL, A HJJ: Incidence and risk factors of pancreatitis in obstructive jaundice patients after percutaneous implantation of self-expandable metallic stents. Hepatobiliary Pancreatic Diseases International. 2020;23:0.

2. Jeong-Hyun J. Byeong-Ho, Park: Suprapapillary versus Transpapillary Stent Implantation for Malignant Biliary Obstruction: Which Is Better? Journal of Vascular Interventional Radiology. 2015;26:573-82.

3. Ma J, Luo J, Gu J, Liu Q, Liu L, Zhang W, Zhang Z, Yan Z. Malignant obstructive jaundice treated with intraluminal implantation of lodine- 125 seed strands and metal stents: An analysis of long-term outcomes and prognostic features. Brachytherapy. 2018;17(4):689-95.

4. Krishnavel VC. The role of ERCP in benign diseases of the biliary tract. Gastrointest Endosc. 2015;81(4):795-803.

5. Bernon MM, Shaw J, Burmeister S, Chinnery G, Hofmeyr S, Kloppers JC, Jonas E, Krige JE. Distal malignant biliary obstruction: A prospective randomised trial comparing plastic and uncovered selfexpanding metal stents in the palliation of symptomatic jaundice. South African journal of surgery Suid-Afrikaanse tydskrif vir chirurgie. 2018;56(1):30-4.

6. Meng QQ, Zhao SB, Wang ZJ, Shen Z, Bai Y. Incidence and risk factors for post-ERCP pancreatitis in pancreas divisum patients without chronic pancreatitis. Scand J Gastroenterol. 2020;55(6):1-5.

7. Inamdar S, Slattery E, Bhalla R, Sejpal DV, Trindade AJ. Comparison of Adverse Events for Endoscopic vs Percutaneous Biliary Drainage in the Treatment of Malignant Biliary Tract Obstruction in an Inpatient National Cohort. Jama Oncology. 2016;2(1):112-7.

8. Sohn SH, Park JH, Kim KH, Kim TN. Complications and management of forgotten long-term biliary stents. World J Gastroenterol. 2017;23(4):622-8.

9. Ming-Tao S, Yu-Xiao YU, Kai-Fei Z, Rong-Shu S. Complications of PTCD/PTBS treatment of malignant obstructive jaundice and its prevention: current progress in clinical research. Hainan Medical Journal. 2018;11:1564-7. 
10. Sol YL, Kim CW, Jeon UB, Lee NK, Kim S, Kang DH, Kim GH. Early infectious complications of percutaneous metallic stent insertion for malignant biliary obstruction. Ajr Am J Roentgenol. 2010;194(1):261-5.

11. Portelli M, Jones CD, Surgery DOG, Ayr UH. Severe acute pancreatitis: pathogenesis, diagnosis and surgical management. Hepatobiliary Pancreatic Diseases International. 2017;16(2):155-9.

12. Hsiang-Yao S. Wen-Hung, Hsu, Chao-Hung, Kuo: Postendoscopic retrograde cholangiopancreatography pancreatitis. Kaohsiung J Med Sci. 2019;35(4):195-201.

13. Andrea T, Francesco S, Prampero Vd. Rosario, Landi, Vincenzo, Bove, Pietro, Familiari: Fully covered self-expandable metal stents to dilate persistent pancreatic strictures in chronic pancreatitis: longterm follow-up from a prospective study. Gastrointest Endosc. 2018;88(6):939-46.

14. Foster BR, Jensen KK, Bakis G, Shaaban AM, Coakley FV. Revised Atlanta Classification for Acute Pancreatitis: A Pictorial Essay. Radiographics A Review Publication of the Radiological Society of North America Inc. 2016;36(3):675-87.

15. Cancer NIO. Common Terminology Criteria for Adverse Events (CTCAE) v4.0. 2009.

16. Jáen KC, Archibugi L, Poropat G, Korpela T, Capurso G, Maisonneuve P, Aparicio JR, Casellas JA, Arcidiacono PG, Mariani A. Chronic use of statins and acetylsalicylic acid and incidence of postERCP acute pancreatitis. Data from the STARK project, a prospective international, multicenter, cohort study. Pancreatology. 2019;19(2):189-90.

17. Ding X, Zhang FC, Wang YJ. Risk factors for post-ERCP pancreatitis: A systematic review and metaanalysis. Surgeon Journal of the Royal Colleges of Surgeons of Edinburgh Ireland. 2015;13(4):21829.

18. Lee TH, Choi JH, Park DH, Song TJ, Kim MH. 273 Similar Efficacies of Endoscopic Ultrasound-Guided Transmural and Percutaneous Drainage for Malignant Distal Biliary Obstruction. Clinical Gastroenterology \& Hepatology the Official Clinical Practice. Journal of the American Gastroenterological Association. 2016;14(7):1011-9.

19. Sugawara S, Arai Y, Sone M, Katai H. Frequency, Severity, and Risk Factors for Acute Pancreatitis After Percutaneous Transhepatic Biliary Stent Implantation Across the Papilla of Vater. Cardio Vascular Interventional Radiology. 2017;40:1904-10.

20. Kazumichi K. Risk factors for pancreatitis following transpapillary self-expandable metal stent implantation. Surgical endoscopy. 2012;26(3):771-6.

21. Long Jin Y, Zou. Expert consensus of percutaneous transhepatic biliary drainage and stent implantation in treatment of obstructive jaundice (2018 Edition). Chinese Journal of Interventional Imaging Therapy. 2019;16(1):2-7.

22. Zhang Z, Pang Y, Qiu Z. Clinical efficacy of ulinastatin combined with somatostatin in the treatment of severe acute pancreatitis in emergency department. Journal Of Taishan Medical College. 2019;40(3):207-10.

23. Chao Liu L, Zhang. Somatostatin and its analogues combined with proton pump inhibitor in prevention of post-ERCP pancreatitis: a meta-analysis. Journal of Clinical Hepatobiliary. 
2015;31(9):1464-8.

24. Jing-Wei N. Effect of somatostatin combined with proton pump inhibitor on severe acute pancreatitis and its effect on diamine oxidase and D-lactose. Journal of Medical Forum. 2017;38(6):5-8.

25. Ma X, Tang C, Huang Z, Zhang M, Liu F, Wang C, Wang R, Huang, Tong, Ling Liu: Effect of Proton Pump Inhibitors on Severe Acute Pancreatitis--a Prospective Randomized Trial. Journal of Sichuan University (Medical Science Edition) 2017;48(6):933-936.

26. Scarpignato C, Gatta L, Zullo A, Blandizzi C, Group S-A-F. Italian Society of Pharmacology tIAoHG, the Italian Federation of General P: Effective and safe proton pump inhibitor therapy in acid-related diseases - A position paper addressing benefits and potential harms of acid suppression. BMC Med. 2016;14(1):179-214.

27. Yadlapati R, Kahrilas PJ. When is proton pump inhibitor use appropriate? BMC Med. 2017;15:36-40.

28. Yadlapati R, Kahrilas PJ. The "dangers" of chronic proton pump inhibitor use. J Allergy Clin Immunol. 2018;141:79-81.

29. Sari Rty J, Sand M, Pulkkinen,Marti, Matikainen. Isto Nordback: Post-ERCP pancreatitis: reduction by routine antibiotics. J Gastrointest Surg. 2001;5(4):339-45.

\section{Figures}




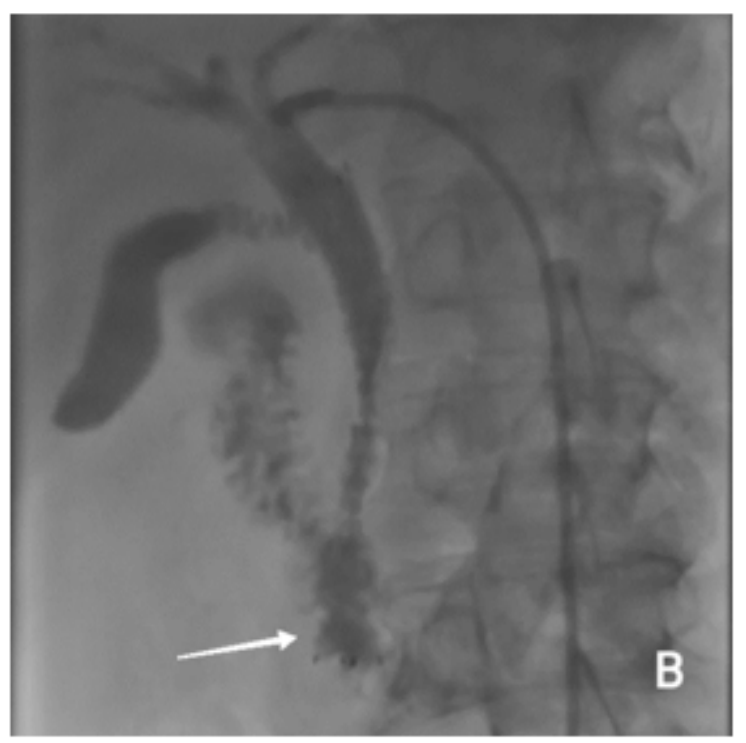

\section{Figure 1}

A 72-year-old male with malignant distal biliary obstruction underwent PTBS, who developed postoperative pancreatitis. A: The site of obstruction was located in the distal common bile duct (PTC). B: The stent implantation across the duodenal papilla (PTC). 


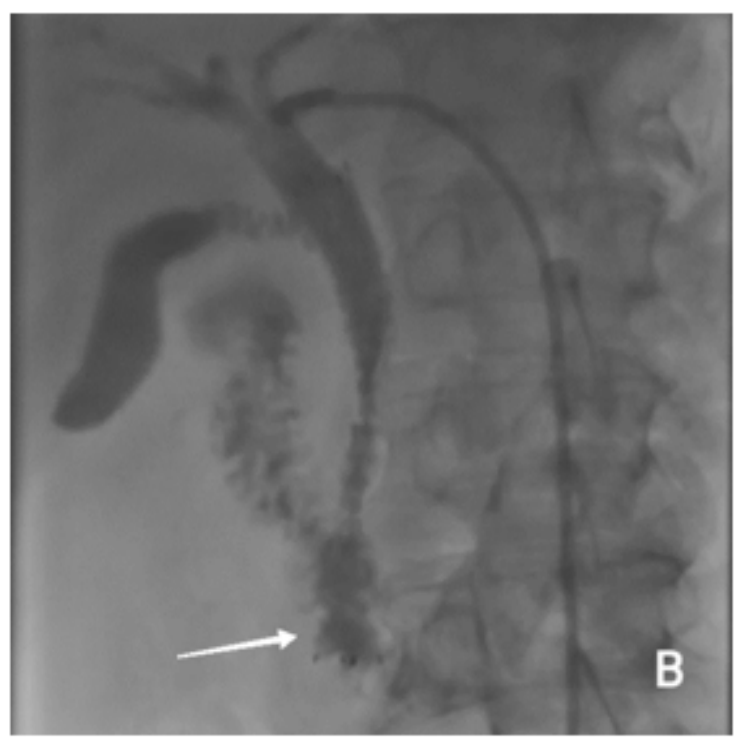

\section{Figure 1}

A 72-year-old male with malignant distal biliary obstruction underwent PTBS, who developed postoperative pancreatitis. A: The site of obstruction was located in the distal common bile duct (PTC). B: The stent implantation across the duodenal papilla (PTC). 

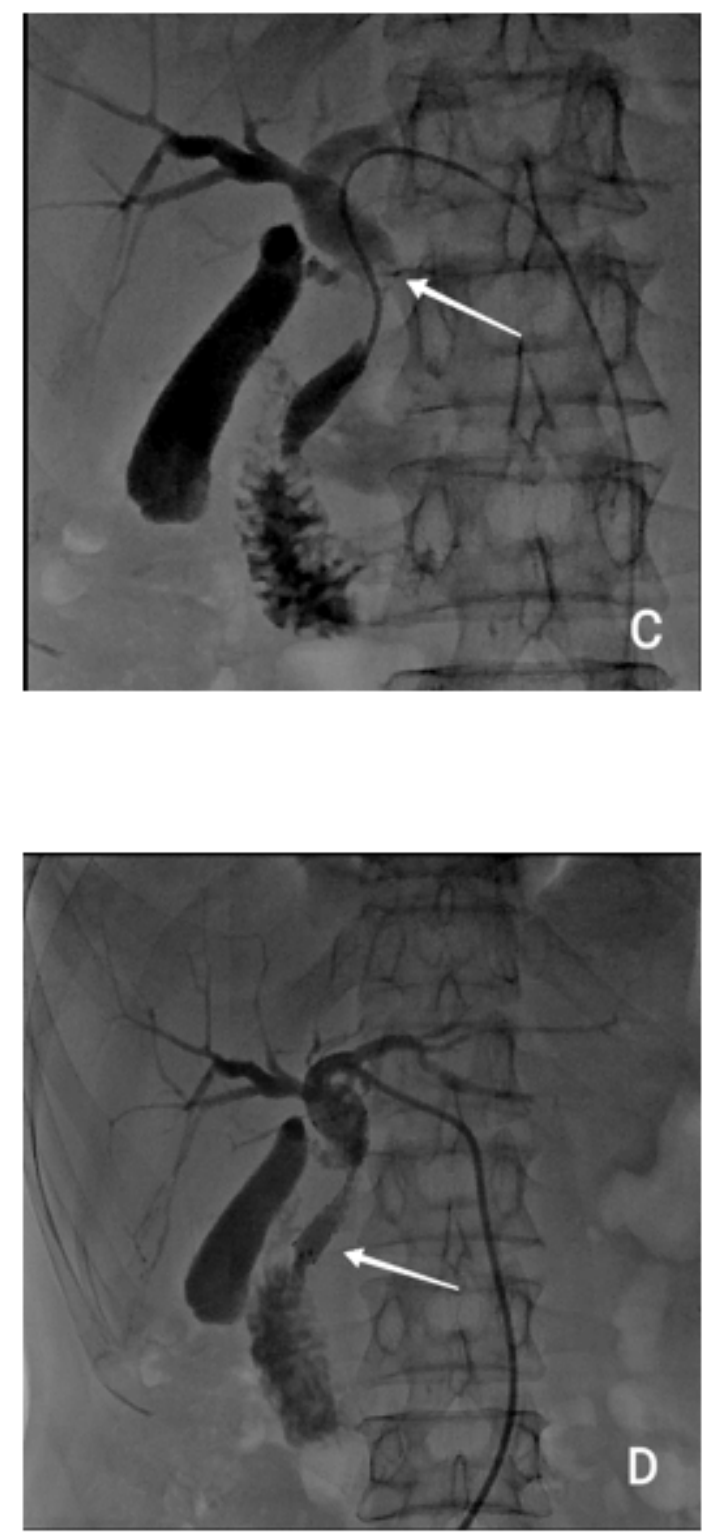

\section{Figure 2}

A 65-year-old male with malignant distal biliary obstruction underwent PTBS without postoperative pancreatitis. C: The site of obstruction was located in the upper common bile duct (PTC). D: The stent was not placed across the duodenal papilla (PTC). 

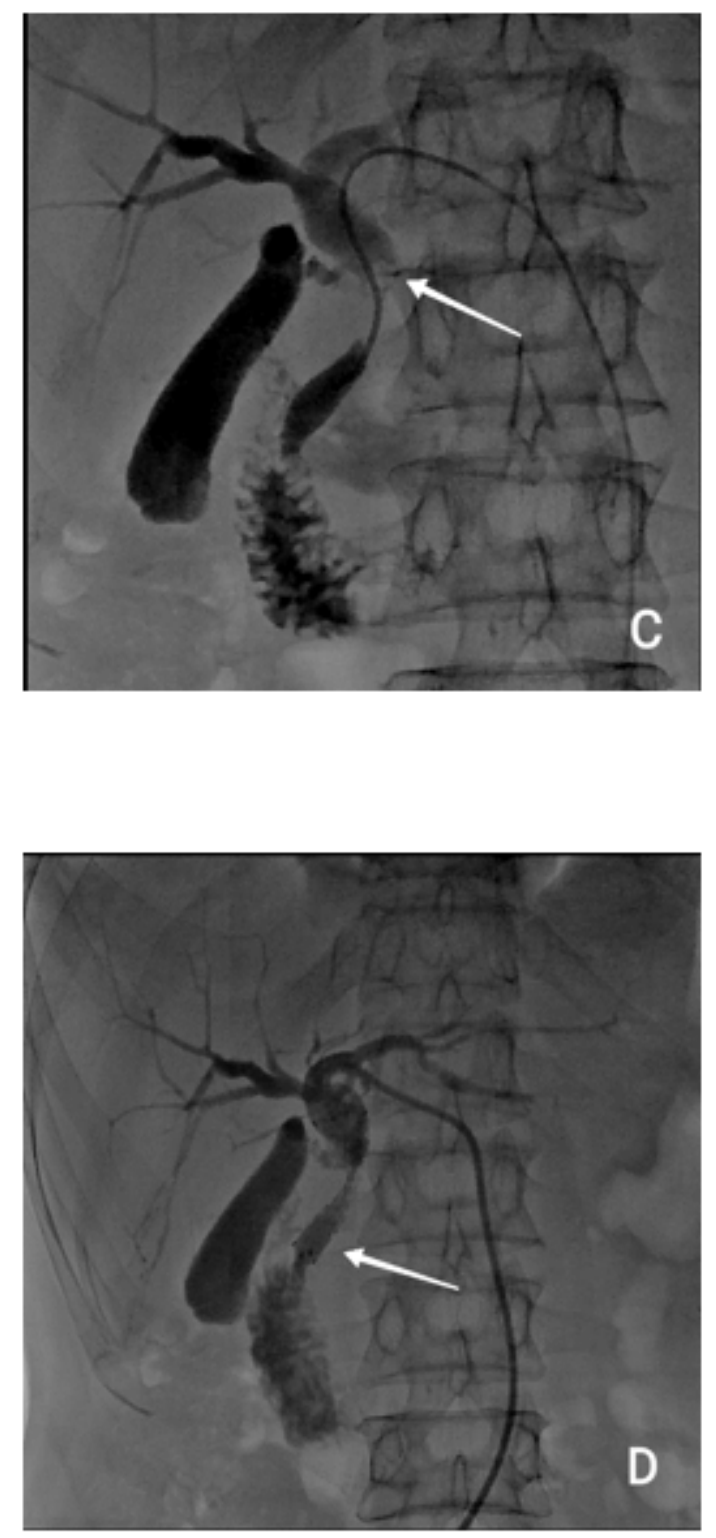

\section{Figure 2}

A 65-year-old male with malignant distal biliary obstruction underwent PTBS without postoperative pancreatitis. C: The site of obstruction was located in the upper common bile duct (PTC). D: The stent was not placed across the duodenal papilla (PTC). 